\title{
Why are the Refugees Children Better Nourished than the Host? Findings from the Uganda's Largest Refugee Settlement Bidi Bidi
}

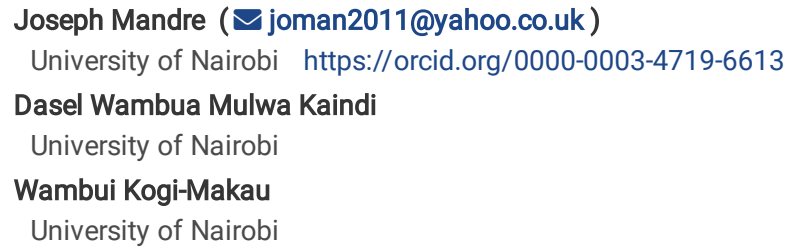

\section{Research Article}

Keywords: nutritional status, under fives, Bidi Bidi Refugee Settlement, host population

Posted Date: June 15th, 2021

DOI: https://doi.org/10.21203/rs.3.rs-592172/v1

License: () (i) This work is licensed under a Creative Commons Attribution 4.0 International License. Read Full License 


\section{Abstract}

About 25.4 million people worldwide are living as refugees of whom 1.36 million are resident in Uganda. Uganda is the largest refugee host in Africa and third globally. The refugees in this study were from South Sudan. The burden of refugee's presence on the host is rarely discussed by funding agencies. The objective of this study was to determine the nutritional status of children in a refugee settlement and to elucidate the factors that contribute to poor nutritional status of the children in the settlement in order to illuminate strengths or weaknesses in the host population. A total of 340 mother-child dyads participated in this study.

The study established an overall prevalence of $14.1 \%$ for underweight and a global acute malnutrition of $3.9 \%$ for the two groups (refugees $3.6 \%$; host $4.1 \%$ ) combined. It recorded stunting prevalence of $27.0 \%$ and $22.4 \%$ in the host and refugee populations, respectively. In ascending order, five factors contributed to poor nutritional status; household size $\left(\mathrm{OR}^{\mathrm{a}}=1.34,1.92\right)$, episode of illness (wasting, stunting and underweight) $\left(\mathrm{OR}^{\mathrm{a}}=1.47,1.49,1.97\right)$, being a host $($ wasting and stunting) $\left(\mathrm{OR}^{\mathrm{a}}=1.81,1.36\right)$ and lack of deworming $\left(\mathrm{OR}^{\mathrm{a}}=3.2,2.13\right)$.

Even though the host had relatively better nutrient intake, compared to the refugees, they were nutritionally worse off, as the refugee children had better nutritional status. Therefore, the host should be equally targeted for nutritional interventions. The government of Uganda should thereby formulate and enforce policy that allows the host to benefit equally from food relief during emergencies.

\section{Introduction}

The World Bank estimates that about two billion people are living in countries affected by crisis (1), 36 nations or territories are categorized as being in instability, in the recent past (2). Globally, man-made disasters, such as civil war and natural disasters, such as, drought and floods are major causes of fragility. Kiess et al (3) estimates a $50 \%$ rise in population of people living in unstable areas by 2030 . Universally, about 40 million people are living as Internally Displaced Persons (IDPs) and 25.4 million as refugees (4). According to Carter (2018) (5) this level of population movement is the highest in the modern time with about 201 million people affected and in need of humanitarian support. Agreeing with Caroline (2018) (6), two thirds of refugees globally are from South Sudan, Somalia, Afghanistan, Myanmar and Syria. Furthermore, majority of the refugees are below the age of 18 years. This kind of movement results into malnutrition due to loss of farmlands and livelihoods compounded by high morbidity rates among the population (7). In addition, approximately 124 million people in 51 countries in the world experience significant food access problems (3), which puts further strain to fragility.

Uganda is the third largest refugee-hosting nation in the world after Turkey and Pakistan as of June 2018, with 1.36 million refugees (8). Despite these extreme numbers, distributed in 12 districts, no comprehensive study exists to show how the presence of refugees affects the host population. According to the policy report (2004) (9), the consequences of refugees and internally displaced persons on the host population goes unmentioned. Limited data exists on the consequences of refugee's presence on the health and nutrition well-being of resident populations (10). Decision on how to distribute food aid in settlements is a very difficult duty (11). Besides, refugees are settled in remote localities with inadequate social amenities, such as; schools, health facilities and other infrastructure. Settling refugees in such locations on many occasions - physically, politically, culturally and socio-economically attracts more burden than blessings to the poor host community households.

The national prevalence of wasting in Uganda is 3.6\% (12). Every year, the number of children who need nutritional care in the management of severe acute malnutrition (SAM) is 233,000 . The national prevalence of stunting, $29 \%$, is below the $30 \%$ World Health Organization (WHO) threshold (12). Similarly, in the refugee settlement, the overall prevalence of wasting and stunting is $9.5 \%$ and $20.4 \%$, respectively (13). Whereas wasting is above the WHO threshold in the refugee settlement, stunting is within the acceptable limit. Availability and access to adequate food is a burden to both refugees and host communities especially for children 6-59 months of age (14). The dietary intake of refugees chiefly depends on the food aid distributed by humanitarian agencies (15). Refugees sell part of food rations to pay for other household needs (14). The host population, who are similarly vulnerable to food in turn purchase the relief foods (16). The variability in providing food and nutrition assistance in emergency for children 6-59 months of age prompted us to examine for differences in nutritional status among children in the host and refugee population of Bidi Bidi settlement in Yumbe district of Uganda, three years after the July 2016 political crisis in South Sudan. The objective of this study was to assess and compare the factors that contribute to poor nutritional status of children in the settlement and the host populations between $19^{\text {th }}$ June 2019 and $9^{\text {th }}$ July 2019.

\section{Materials And Methods}

\subsection{Study setting}

This study targeted children 6-59 months of age living in two of the five Zones in Bidi Bidi settlement in Yumbe district, Uganda (Fig 1). Zone one located in Romogi sub-county and Zone two located in Kochi sub-county. Both the host and the refugee population provided data. The two host sub-districts have suffered directly or indirectly due to the presence of the refugees in terms of access to food items and nutritional services.

\subsection{Study design}

This study used comparative analytical cross-sectional design on children 6-59 months of age in Ramogi and Kochi in Bidi Bidi settlement (zone 1 and 2) in Yumbe district, Uganda.

\subsection{Sample size determination}

To compute the sample size, the study used a design effect (DEFF) of two (2) and a prevalence of Global Acute Malnutrition (GAM) of 11.8\% (13) in a multistage cluster sampling that yielded a sample size of 340 children. 
Villages were randomly selected from the sampling frame of villages in the host and refugee population. In Zone one, data were collected in village 4, 5, 6, 7 and 13 for the refugee population and in the surrounding host villages of Zone 1 (Barakala, Luzira, Amatanga, Onoko and Likichonga). In Zone 2, village 6 and

7 (refugee settlement) and Swinga village, respectively, represented the refugee and host populations. Households and the study children, in each village in the settlement and the host population were chosen using simple random sampling. In households where more than one index child was found, the youngest child was selected in this study.

\subsection{Data collection and quality control}

The study used Open Data Kit (ODK) mobile data collection platform supported with Ona.io server. It employed 13 members of Village Health Teams, commonly referred to as VHTs, as data enumerators. The enumerators received pre data collection training that integrated pretesting of data tools at Linga village (not part of the sample population).

The questionnaire that applied as the main study tool had the following sections; demographic and socio-economic characteristics, health seeking behavior, household food security situation and feeding behavior and practices in the household. Weight measurement was taken using Digital Uniscale (Seca, Deutschland) while graduated wooden board was used to measure height/length. Two measurements were taken for anthropometry and average computed for analysis, to reduce measurement error. Bilateral pitting oedema was checked on both feet of the study children. Dietary practices were measured using the FAO individual dietary diversity score (17) form that included seven food groups. The mothers, as the principal respondents in this study, listed the different food groups eaten by the child in the 24 hours prior to the study. To obtain individual dietary diversity score (DDS) of the study children, 24 -hour recall data was used. To determine the nutrient intake for the two-population groups, 24-hour recall data was used to measure nutrient intake. The adequacy of nutrient intake were determined using recommended daily allowance (RDA) of Kenya adopted from WHO/FAO (1998) (18)

\subsubsection{Ethical and human rights considerations}

Ethical approval for this study was obtained from Gulu University Research Ethics Committee (GUREC) while the Office of the Prime Minister (OPM) issued the research permit. The local district authorities were similarly consulted about this study. The mothers or caregivers endorsed translated and informed written consent forms before being interviewed. The information collected from households were carefully protected and kept private.

\subsubsection{Data analysis}

The raw data was downloaded from the ona.io server for cleaning, coding and recoding. The study used the Emergency Nutrition Assessment (ENA) software to convert anthropometric data into indices for children 6-59 months of age. Further in-depth data analysis used Statistical Package for Social Sciences (SPSS) version 20.0 and Python version 3.7.3. The Chi Square $\left(x^{2}\right)$ and Multivariate Logistic Regression (MLR) analysis established the level of association between nutritional status and other variables.

\section{Results}

\subsection{Demographic and socio-economic status of households in the host and refugee population}

A total of 340 households participated in the study of whom, 170 represented the host population and 170-refugee population. The demographic and socioeconomic characteristics of the host and refugee groups are demonstrated in Table 1 . The number of male children in the refugee population was higher 108 $(63.5 \%)$ compared to that of the host $82(48.2 \%)(p=0.00)$. There was no significant difference in the distribution of the study children $(p=0.196)$ according to age, but most of the children were older than 11 months. Few male respondents (caregivers of the children) participated in this study, 7 (4.1\%) in the host and $14(8.2 \%)$ in the refugee population, but the statistical difference was not significant. Majority of the households in the host population were male-headed 139 $(81.8 \%)$ unlike among the refugee population where female-heads predominated, $93(55 \%)(p=0.00)$. There was no difference in the age of household heads for the two sites, but the majority were of the ages above 29 years old. The proportion of household heads with age below 18 years were very low $(0.6 \%$ versus $1.8 \%$ ) in host and refugee populations, respectively.

The socio-economic characteristics of the host and the refugee populations is shown in table 2 . There was no significant statistical difference in the marital status of at the two sites ( $p>0.05)$, however, the married constituted the majority, $156(91.8 \%)$ and $145(85.8 \%)$, for host and refugee, respectively. The household sizes were not different for the two sites. Many of the households had medium size members (5-10), host 115 (67.6\%) and refugees 127 (74.7\%). The host had better income status compared to the refugees $(p=0.00)$. Households with low-income status, that is, living below USD 54 per month, were the majority, $87(51.2 \%)$ for the host and 135 (79.4\%) for the refugees. The distribution of households by religion, education and occupations of household heads showed significant statistical differences between the two-study populations. Greater number of the host population were Muslim 159 (93.5\%) whereas the refugees were predominantly Catholic 125 (73.5\%). The literacy rate of household heads in the study area was low whereby attendance of formal education and completion rate was below $20 \%$ for the two study sites. About $62(36.5 \%)$ in the host and $97(57.4 \%)$ of the household heads never attended school among the host and refugee populations respectively. Farming was a more common occupation among the household heads in the host population 82 (48.2\%) compared to 25 (14.8\%) in the refugee group of whom $70.4 \%$ were unemployed.

Table 1: Demographic characteristics of the host and the refugee populations 


\begin{tabular}{|c|c|c|c|c|c|}
\hline \multirow[t]{2}{*}{$\mathrm{N}=340$} & \multicolumn{2}{|c|}{$\begin{array}{c}\text { Host } \\
\mathrm{N}=170\end{array}$} & \multicolumn{2}{|c|}{$\begin{array}{c}\text { Refugees } \\
\mathrm{N}=170\end{array}$} & \multirow[t]{2}{*}{$\mathrm{X}^{2}$ (p-Value) } \\
\hline & $\mathrm{n}$ & $\%$ & $\mathrm{n}$ & $\%$ & \\
\hline Gender of children & & & & & $8.1(0.00)$ \\
\hline Male & 82 & 48.2 & 108 & 63.5 & \\
\hline Female & 88 & 51.8 & 62 & 36.5 & \\
\hline Age of children & & & & & $4.7(0.19)$ \\
\hline 6-11 Months & 30 & 17.6 & 17 & 10 & \\
\hline 12-23 Months & 56 & 32.9 & 56 & 32.9 & \\
\hline 24-35 Months & 38 & 22.4 & 41 & 24.1 & \\
\hline 36-59 Months & 46 & 27.1 & 56 & 32.9 & \\
\hline Gender respondents & & & & & $2.5(0.88)$ \\
\hline Male & 7 & 4.1 & 14 & 8.2 & \\
\hline Female & 163 & 95.9 & 156 & 91.8 & \\
\hline Gender of household head & & & & & $49.5(0.00)$ \\
\hline Male & 139 & 81.8 & 76 & 45 & \\
\hline Female & 31 & 18.2 & 93 & 55 & \\
\hline Age of household head & & & & & $2.1(0.57)$ \\
\hline$<18$ Years & 1 & 0.6 & 3 & 1.8 & \\
\hline 18-28 Years & 45 & 26.5 & 48 & 28.4 & \\
\hline 29-39 Years & 72 & 42.4 & 75 & 44.4 & \\
\hline$>40$ Years & 52 & 30.6 & 43 & 25.4 & \\
\hline
\end{tabular}

n sample size; \% percentage; $x^{2}$ Chi Square

Table 2: Socio-economic characteristics of the host and the refugee populations

\begin{tabular}{|c|c|c|c|c|c|}
\hline \multirow[t]{2}{*}{$\mathrm{N}=340$} & \multicolumn{2}{|c|}{$\begin{array}{c}\text { Host } \\
\mathrm{N}=170\end{array}$} & \multicolumn{2}{|c|}{$\begin{array}{c}\text { Refugees } \\
\mathrm{N}=170\end{array}$} & \multirow[t]{2}{*}{$\mathrm{X}^{2}$ (p-Value) } \\
\hline & $\mathrm{n}$ & $\%$ & $\mathbf{n}$ & $\%$ & \\
\hline Marital status of household head & & & & & $4.7(0.32)$ \\
\hline Married & 156 & 91.8 & 145 & 85.8 & \\
\hline Separated & 7 & 4.1 & 16 & 9.5 & \\
\hline Divorced & 2 & 1.2 & 1 & 0.6 & \\
\hline Single & 1 & 0.6 & 2 & 1.2 & \\
\hline Widowed & 4 & 2.4 & 5 & 3 & \\
\hline Household size & & & & & $3.7(0.16)$ \\
\hline Small (1-4) & 40 & 23.5 & 26 & 15.3 & \\
\hline Medium (5-10) & 115 & 67.6 & 127 & 74.7 & \\
\hline Large $(>11)$ & 15 & 8.8 & 17 & 10 & \\
\hline Household income (USD) & & & & & $35.0(0.00)$ \\
\hline Less than 54 & 87 & 51.2 & 135 & 79.4 & \\
\hline $54.5-135$ & 70 & 41.2 & 35 & 20.6 & \\
\hline $135.5-271$ & 13 & 7.6 & 0 & 0 & \\
\hline Religion of the household & & & & & $280.2(0.00)$ \\
\hline Catholic & 11 & 6.5 & 125 & 73.5 & \\
\hline Protestant & 0 & 0 & 40 & 23.5 & \\
\hline Muslim & 159 & 93.5 & 5 & 2.9 & \\
\hline Education level of household head & & & & & $32.8(0.00)$ \\
\hline Never went to school & 62 & 36.5 & 97 & 57.4 & \\
\hline Primary education & 40 & 23.5 & 47 & 27.9 & \\
\hline Secondary education & 56 & 32.9 & 23 & 13.5 & \\
\hline Tertiary Education & 12 & 7.1 & 2 & 1.2 & \\
\hline Occupation of household head & & & & & $108.4(0.00)$ \\
\hline Farmer & 82 & 48.2 & 25 & 14.8 & \\
\hline Salaried Employed & 13 & 7.6 & 7 & 4.1 & \\
\hline Businessperson & 16 & 9.4 & 5 & 3 & \\
\hline Casual laborer & 6 & 3.5 & 1 & 0.6 & \\
\hline Student & 1 & 0.6 & 1 & 0.6 & \\
\hline Unemployed & 26 & 15.3 & 119 & 70.4 & \\
\hline Others & 26 & 15.3 & 11 & 6.5 & \\
\hline
\end{tabular}

n sample size; \% percentage; $\mathrm{x}^{2}$ Chi Square

\subsection{Nutritional status of children in the host and refugee population}

While the prevalence of GAM was acceptable in the study setting (less than 5\%), the children in the host community had worse nutritional status $4.1 \%$ compared to the refugees $3.6 \%$, though the differences were not statistically significant. Table 3 illustrates the nutritional status by gender and population. 
There was no statistical difference in the nutritional status by gender and population group. The prevalence of stunting among the host children was higher, though not statistically different, from that of the refugees; $27 \%$ and $22.4 \%$, respectively. Prevalence of underweight was the same in the host and refugee populations; $14.1 \%$.

Table 3: Nutritional status of children by gender and population groups

\begin{tabular}{|c|c|c|c|c|c|c|}
\hline & Female & Male & & Host & Refugees & \\
\hline & $\%(n=150)$ & $\begin{array}{c}\% \\
(n=170)\end{array}$ & $\mathrm{X}^{2}(\mathrm{p}$-Value $)$ & $\%(n=170)$ & $\%(n=170)$ & $X^{2}(p-$ Value $)$ \\
\hline Wasting & & & $0.8(0.9)$ & & & $0.2(0.9)$ \\
\hline No & 97 & 96 & & 95.9 & 96.5 & \\
\hline Yes & 3.4 & 4.2 & & 4.1 & 3.6 & \\
\hline Stunting & & & $3.2(0.4)$ & & & $2.1(0.5)$ \\
\hline No & 79 & 73 & & 73 & 77.6 & \\
\hline Yes & 21 & 27 & & 27 & 22.4 & \\
\hline Underweight & & & $5.0(0.2)$ & & & $2.3(0.5)$ \\
\hline No & 90 & 83 & & 85.9 & 85.9 & \\
\hline Yes & 10 & 17 & & 14.1 & 14.1 & \\
\hline
\end{tabular}

n sample size; \% percentage; $x^{2}$ Chi Square value

\subsubsection{Multivariate logistic regression for wasting}

The adjusted odds ratio $\left(\mathrm{OR}^{\mathrm{a}}\right)$ showed that being a host was a risk factor to wasting $\left(\mathrm{OR}^{\mathrm{a}}=1.81 ; \mathrm{p}=0.36 ; 95 \% \mathrm{Cl} 0.51-6.39\right)$. Results generated by multivariate logistic regression (MLR) analysis for wasting as the dependent variable and associated factors as independent variables are depicted in table 4 . Children who were not dewormed were at a higher risk of becoming wasted $\left(\mathrm{OR}^{\mathrm{a}}=3.20 ; \mathrm{p}=0.22 ; 95 \% \mathrm{Cl} 0.49-20.75\right)$ and there was no statistical significant difference between the two populations. Child illness was a potential risk factor to wasting $\left(\mathrm{OR}^{\mathrm{a}}=1.47 ; \mathrm{p}=0.56 ; 95 \% \mathrm{Cl} 0.40-5.44\right)$ for the two population groups. Being medium household size (5-10 members) $\left(\mathrm{OR}^{\mathrm{a}}=1.29 ; \mathrm{p}=0.76 ; 95 \% \mathrm{Cl} 0.25-6.63\right)$ and presence of palmar pallor $\left(\mathrm{OR}^{\mathrm{a}}=2.13 ; \mathrm{p}=0.31 ; 95 \% \mathrm{Cl} 0.05-9.13\right)$ were additional associated factor for wasting. The important protective factors to wasting were being a female $\left(0 \mathrm{R}^{\mathrm{a}}=0.64 ; \mathrm{p}=0.46 ; 95 \% \mathrm{Cl} 0.20-2.08\right)$ and having a dietary diversity score of $\geq 4$ food groups $\left(\mathrm{OR}^{\mathrm{a}}=0.39 ; \mathrm{p}=0.29 ; 95 \% \mathrm{Cl} 0.07-2.21\right)$.

Table 4: Results of multivariate logistic regression for wasting and risk factors

\begin{tabular}{lcccc}
\hline & & & \multicolumn{2}{c}{$\mathbf{9 5 \%}$ Confidence Interval } \\
\cline { 4 - 5 } & OR $^{\mathrm{a}}$ & p-Value & $5 \%$ & $95 \%$ \\
\cline { 2 - 5 } Household income of less than USD 54 & 0.30 & 0.14 & 0.06 & 1.47 \\
Being a female child & 0.64 & 0.46 & 0.20 & 2.08 \\
\hline Lack of deworming & 3.20 & 0.22 & 0.49 & 20.75 \\
Not fully immunized & 1.00 & 1.00 & 0.20 & 5.03 \\
\hline Presence of palm pallor & 2.13 & 0.31 & 0.50 & 9.13 \\
\hline Child being ill & 1.47 & 0.56 & 0.40 & 5.44 \\
Host population & 1.81 & 0.36 & 0.51 & 6.39 \\
\hline Dietary diversity score- $\geq 4$ food groups & 0.39 & 0.29 & 0.07 & 2.21 \\
Household of medium size & 1.29 & 0.76 & 0.25 & 6.63 \\
Household of large size & 0.68 & 0.77 & 0.05 & 8.92 \\
\hline Child age & 0.94 & 0.06 & 0.88 & 1.00 \\
\hline
\end{tabular}

$\mathrm{OR}^{\mathrm{a}}$ adjusted Odds Ratio

\subsection{Associated factors for stunting in Bidi Bidi refugee child population}

The low income, (less than USD 54 per month), households in the refugee population had high prevalence of stunting $71.0 \%$ compared to the host, $52.0 \%$, in the same income group. Table 5 shows the relationship between stunting, household income and household size in Bidi Bidi settlement. Overall, the host had better income status compared to the refugees. There was no statistical significant difference in stunting and estimated household income in the study setting $(\mathrm{p}=0.51)$. Larger households had relatively lower prevalence of stunting and with the host being better, $7.0 \%$, than the refugees, $13.0 \%$. In smaller households, the prevalence of stunting was lower in the refugee population $11.0 \%$ compared to the host $26.0 \%$. Generally, the refugees had acceptable level of stunting compared to the host according to $\mathrm{WHO}$ and there was no statistical significant difference in this relationship $(p=0.99)$.

Table 5: Relationship between stunting, household income and household size in Bidi Bidi Settlement 


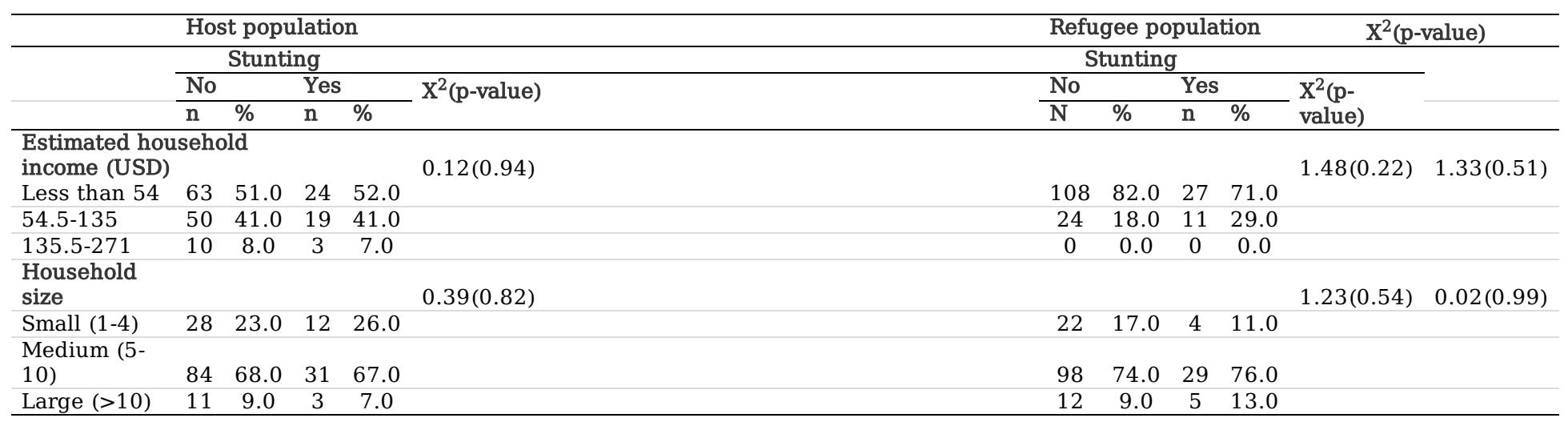

n sample size; \% percentage; $x^{2}$ Chi Square valuen

sample size; \% percentage; $x^{2}$ Chi Square value

\subsection{Multivariate logistic regression for stunting}

Children in the host population were at a higher risk of stunting compared to the refugees $\left(\mathrm{OR}^{\mathrm{a}} 1.36 ; \mathrm{p}=0.28 ; 95 \% \mathrm{Cl} 0.8-24\right)$ but the difference was not statistically significant. Table 6 shows logistic regression for stunting as the dependent variable and associated factors as independent variables. The other factors that contributed to stunting were lack of hand washing $\left(\mathrm{OR}^{\mathrm{a}} 3.06 ; \mathrm{p}=0.02 ; 95 \% \mathrm{Cl} 1.3-7.8\right)$ and there was a statistically significant difference. Child illness $\left(O R^{a} 1.49 ; p=0.17 ; 95 \% \mathrm{Cl} 0.9-2.6\right)$ and household size (greater than 10 members) $\left(O R^{a} 1.34 ; p=0.35 ; 95 \%\right.$ Cl $\left.0.8-2.5\right)$. The potential protective factors to stunting were being a female child $\left(\mathrm{OR}^{\mathrm{a}} 0.62 ; \mathrm{p}=0.08 ; 95 \% \mathrm{Cl} 0.4-1.1\right)$, deworming $\left(\mathrm{OR}^{\mathrm{a}} 0.65 ; \mathrm{p}=0.18 ; 95 \% \mathrm{Cl} 0.4-1.3\right)$, individual dietary diversity score of at least four food groups $\left(\mathrm{OR}^{\mathrm{a}} 0.7 ; \mathrm{p}=0.26 ; 0.4-1.4\right)$.

Table 6: Results of multivariate logistic regression for stunting and risk factors

\section{5\% Confidence Interval}

\begin{tabular}{lcrrrrr} 
& Coef & Std err & OR $^{\mathrm{a}}$ & $\mathrm{p}$-Value & $\mathbf{5 \%}$ & $\mathbf{9 5 \%}$ \\
\hline Being a female child & -0.5 & 0.3 & 0.62 & 0.08 & 0.4 & 1.1 \\
Lack of hand washing & 1.2 & 0.5 & 3.06 & 0.02 & 1.3 & 7.8 \\
Lack of deworming & -0.5 & 0.4 & 0.65 & 0.18 & 0.4 & 1.3 \\
Child being ill & 0.4 & 0.3 & 1.49 & 0.17 & 0.9 & 2.6 \\
Host population & 0.4 & 0.3 & 1.36 & 0.28 & 0.8 & 2.4 \\
Dietary diversity score $>=4$ food groups & -0.4 & 0.4 & 0.7 & 0.26 & 0.4 & 1.4 \\
Household of large size & 0.3 & 0.4 & 1.34 & 0.35 & 0.8 & 2.5 \\
Child age & -0.1 & 0.1 & 0.95 & 0.00 & 1 & 1 \\
\hline
\end{tabular}

$\mathrm{OR}^{\mathrm{a}}$ adjusted Odds Ratio; Coef Correlation Coefficient; Std err Standard error

\subsection{Underweight and associated factors in Bidi Bidi settlement}

Underweight was high in the host population, $92 \%$ compared to the refugee population $67 \%$ among children who were partly immunized for age. Table 7 shows the relationship between underweight, immunization status and cultivation in the study area. For children fully immunized, the refugee population had very high prevalence of underweight $33 \%$ compared to the host $8 \%$. There was no statistical significant association between underweight and immunization status in the settlement $(\mathrm{p}=0.28)$. Cultivation was a risk factor to underweight in both the host $88 \%$ and the refugee population $79 \%$. Households who have not cultivated land had lower prevalence of underweight, host population $12 \%$ and refugee population $21 \%$ respectively. There was no statistical significant relationship between underweight and cultivation in the settlement $(p=0.12)$.

Table 7: Prevalence of underweight against immunization status and cultivation in Bidi Bidi Settlement 


\begin{tabular}{|c|c|c|c|c|c|c|c|}
\hline & \multicolumn{2}{|c|}{ Underweight } & \multirow[b]{2}{*}{$\mathrm{X}^{2}(\mathrm{p}$-Value $)$} & \multicolumn{2}{|c|}{$\begin{array}{l}\text { Host population } \\
\text { Underweight }\end{array}$} & \multirow[b]{2}{*}{$\mathrm{X}^{2}$ (p-Value) } & \multirow[t]{2}{*}{$\mathrm{X}^{2}(\mathrm{p}$-Value $)$} \\
\hline & $\begin{aligned} \text { No } & \\
& \% \\
& (\mathrm{n}=146)\end{aligned}$ & $\begin{array}{l}\text { Yes } \\
\% \\
(\mathrm{n}=24) \\
\end{array}$ & & $\begin{array}{l}\text { No } \\
\quad \% \\
(n=145)\end{array}$ & $\begin{array}{c}\text { Yes } \\
\% \\
(n=25) \\
\end{array}$ & & \\
\hline \multicolumn{3}{|c|}{ Fully immunized } & \multirow{3}{*}{$1.4(0.22)$} & & & \multirow{3}{*}{ 7.3(0.007) } & \multirow{3}{*}{$1.14(0.28)$} \\
\hline No & $80 \%$ & $67 \%$ & & $61 \%$ & $92 \%$ & & \\
\hline Yes & $20 \%$ & $33 \%$ & & $39 \%$ & $8 \%$ & & \\
\hline \multicolumn{3}{|c|}{ Have cultivated land } & & & & \multirow[t]{3}{*}{$0.08(0.78)$} & \multirow{3}{*}{$2.38(0.12)$} \\
\hline No & $40 \%$ & $21 \%$ & $2.39(0.12)$ & $17 \%$ & $12 \%$ & & \\
\hline Yes & $60 \%$ & $79 \%$ & & $83 \%$ & $88 \%$ & & \\
\hline
\end{tabular}

$\mathrm{x}^{2}$ Chi Square; $\mathrm{n}$ number of samples; \% percentage

\subsection{Multivariate logistic regression for underweight}

For the two study populations, children who were ill 14 days within the study had higher odds of becoming underweight (OR $1.97 ; \mathrm{p}=0.07,95 \% \mathrm{Cl} 0.95-4.08)$. Table 8 shows logistic regression for underweight as the dependent variable and associated independent variables. The other factors that contributed to underweight were medium household size (5-10 members), (OR $1.92 ; \mathrm{p}=0.10 ; 95 \% \mathrm{Cl} 0.87-4.24)$ and hand washing $\left(O \mathrm{R}^{\mathrm{a}} 1.81 ; \mathrm{p}=0.24 ; 95 \% \mathrm{Cl} 0.68-4.83\right)$ and there was no statistical significant association. The potential protective factor to underweight was being female $\left(0 \mathrm{R}^{\mathrm{a}} 0.46 ; \mathrm{p}=0.03 ; 95 \% \mathrm{Cl} 0.23-0.93\right)$ and this was statistical significant. Dietary diversity score of $>=4$ was likewise a protective factor to underweight $\left(O R^{\mathrm{a}} 0.34 ; \mathrm{p}=0.02 ; 95 \% \mathrm{Cl} 0.14-0.84\right)$ and this was significantly different.

Table 8: Results of multivariate logistic regression for underweight and risk factors

\begin{tabular}{lccccc}
\hline & & & & \multicolumn{2}{c}{$95 \%$ Confidence Interval } \\
\cline { 5 - 6 } & coef & OR $^{\mathrm{a}}$ & $\mathrm{p}$-Value & $5.0 \%$ & $95.0 \%$ \\
\hline Being a female child & -0.8 & 0.46 & 0.03 & 0.23 & 0.93 \\
Lack of hand washing & 0.6 & 1.81 & 0.24 & 0.68 & 4.83 \\
Child being ill & 0.7 & 1.97 & 0.07 & 0.95 & 4.08 \\
Dietary diversity score $>=4$ food group & -1.1 & 0.34 & 0.02 & 0.14 & 0.84 \\
Household of Medium size & 0.7 & 1.92 & 0.10 & 0.87 & 4.24 \\
Child age & -0.1 & 0.92 & 0.00 & 0.89 & 0.96 \\
\hline
\end{tabular}

Coef Correlation Coefficient; $\mathrm{OR}^{\mathrm{a}}$ Adjusted odds ratio

\subsection{Dietary diversity of the host and refugee children}

Generally, the refugee population had better dietary diversity score (DDS) compared to the host population. Table 9 shows the DDS of the host and refugee population. In the host population, the female children had more diverse diet $53.0 \%$ compared to the males $47.0 \%$ whereas in the refugee population, male children had better DDS $71.0 \%$ compared to the female $29.0 \%$. There was no statistical significant difference in terms of gender and DDS in the settlement $(p=0.91)$. In the two-population group, young children had poor DDS and good DDS improved with age. Conversely, the children in the refugee population in older age category (36-59 months) scored better DDS $42.0 \%$ compared to the host $35.0 \%$, respectively. Dietary diversity score in the host and refugee population in the different age categories was significantly different $(p=0.01)$.

In terms of household size, good DDS in the small household size (1-4) and large household size (>10) in both the host $32 \%, 0.0 \%$ and refugee population $10 \%$, $7.0 \%$ was poor. Household size and DDS was statistical significant $(p=0.00)$. Poor DDS was a major contributing factor to stunting in the two-population group, in the host, $33.0 \%$ of the stunted children had low DDS and $24.0 \%$ in the refugee population. There was no significant relationship ( $p=0.97$ ). Underweight was high in children who had low DDS in the study setting, 19.0\% in the host and $18.0 \%$ in the refugee population ( $p=0.00$ ).

Table 9: Dietary diversity score of children in the host and Bidi Bidi settlement 


\begin{tabular}{|c|c|c|c|c|c|c|c|c|c|c|c|}
\hline & \multicolumn{4}{|c|}{ Host Population } & \multicolumn{6}{|c|}{ Refugee Population } & \multirow[t]{3}{*}{$\mathrm{X}^{2}$ (p-value) } \\
\hline & \multicolumn{2}{|c|}{ DDS $<4$} & \multicolumn{2}{|c|}{$\mathrm{DDS}>=4$} & \multirow[t]{2}{*}{$\mathrm{X}^{2}$ (p-value) } & \multicolumn{2}{|c|}{ DDS $<4$} & \multicolumn{2}{|c|}{ DDS $>=4$} & \multirow[t]{2}{*}{$\mathrm{X}^{2}(\mathrm{p}$-value $)$} & \\
\hline & $\mathrm{n}$ & $\%$ & $\mathrm{n}$ & $\%$ & & $\mathrm{n}$ & $\%$ & $\mathrm{n}$ & $\%$ & & \\
\hline Gender of child & & & & & $0.02(0.88)$ & & & & & $1.13(0.29)$ & $0.01(0.91)$ \\
\hline Male & 50 & 50.0 & 32 & 47.0 & & 74 & 61.0 & 34 & 71.0 & & \\
\hline Female & 51 & 50.0 & 36 & 53.0 & & 48 & 39.0 & 14 & 29.0 & & \\
\hline Age group of study child & & & & & $18.66(0.00)$ & & & & & $3.54(0.32)$ & $11.13(0.01)$ \\
\hline 6-11 months & 27 & 26.0 & 3 & 5.0 & & 11 & 9.0 & 6 & 12.0 & & \\
\hline $12-23$ months & 36 & 36.0 & 20 & 29.0 & & 44 & 36.0 & 12 & 25.0 & & \\
\hline 24-35 months & 17 & 17.0 & 21 & 31.0 & & 31 & 25.0 & 10 & 21.0 & & \\
\hline 36-59 months & 21 & 21.0 & 24 & 35.0 & & 36 & 30.0 & 20 & 42.0 & & \\
\hline Household size & & & & & $13.05(0.00)$ & & & & & $2.65(0.27)$ & $9.79(0.00)$ \\
\hline Small (1-4) & 18 & 18.0 & 22 & 32.0 & & 21 & 17.0 & 5 & 10.0 & & \\
\hline Medium (5-10) & 69 & 68.0 & 46 & 68.0 & & 87 & 71.0 & 40 & 83.0 & & \\
\hline Large $(>10)$ & 14 & 14.0 & 0 & 0.0 & & 14 & 12.0 & 3 & 7.0 & & \\
\hline Stunting & & & & & $3.12(0.78)$ & & & & & $0.25(0.61)$ & $2.74(0.97)$ \\
\hline Normal & 68 & 67.0 & 55 & 81.0 & & 93 & 76.0 & 39 & 81.0 & & \\
\hline Stunted & 33 & 33.0 & 13 & 19.0 & & 29 & 24.0 & 9 & 19.0 & & \\
\hline Underweight & & & & & $3.49(0.06)$ & & & & & $4.38(0.036)$ & $8.59(0.00)$ \\
\hline Normal & 82 & 81.0 & 63 & 93.0 & & 100 & 82.0 & 46 & 96.0 & & \\
\hline Underweight & 19 & 19.0 & 5 & 7.0 & $00 \Omega 8$ & 22 & 18.0 & 2 & 4.0 & & \\
\hline Wasting & & & & & $0.00(0.00)$ & & & & & $1.22(0.27)$ & $1.35(0.24)$ \\
\hline Normal & 96 & 95.0 & 66 & 97.0 & & 116 & 95.0 & 48 & 100.0 & & \\
\hline Wasted & 5 & 5.0 & 2 & 3.0 & & 6 & 5.0 & 0 & 0.0 & & \\
\hline
\end{tabular}

n sample size; $x^{2}$ Chi square value; \% percentage; DDS Individual Dietary Diversity Score

\subsection{Nutrient intake in the host and refugee settlement}

The result of 24-hour recall showed that the intake of macronutrient was relatively good in the study area although micronutrient intake was relatively poor. Mostly, large number of children from the host population have met their nutrient intake compared to the refugee population. Table 10 below shows nutrient intake in the study area in a 24-hour recall period. In terms of macronutrient intake, $16.2 \%$ of the children in the host population have not met their daily energy intake compared to $17.7 \%$ in the refugee settlement and there was no statistical significant difference $(p=1)$. Protein food consumption was poor in the refugee settlement: $13.2 \%$ have not met their intake compared to $2.9 \%$ in the host population and there was no statistical significant relationship ( $p=0.06$ ).

In regards to micronutrient intake, consumption of calcium rich food was very poor. The number of children who did not meet recommended intake of calcium was $97.1 \%$ in the host and $100 \%$ among the refugee population and there was no statistical significant relationship ( $p=0.48$ ). The second poorly consumed micronutrient was folate, $6.8 \%$ of the host have not met intake compared to $75.0 \%$ for the refugees ( $p=0.54)$. Vitamin A consumption was better in the refugee population as $80.9 \%$ met recommended intake compared to $63.3 \%$ in the host population; the difference was significant ( $p=0.04)$. Iron intake was similarly good in the two population group, $92.7 \%$ in the host have met intake compared to $88.2 \%$ in the settlement and there was no statistical significant difference $(p=0.56)$. The consumption of vitamin B rich foods was good in the study setting apart from vitamin B1. The intake of Selenium, Vitamin C and Magnesium was good for both groups.

Table 10: Result of nutrient intake in 24 hours by study group populations in Bidi Bidi Settlement 


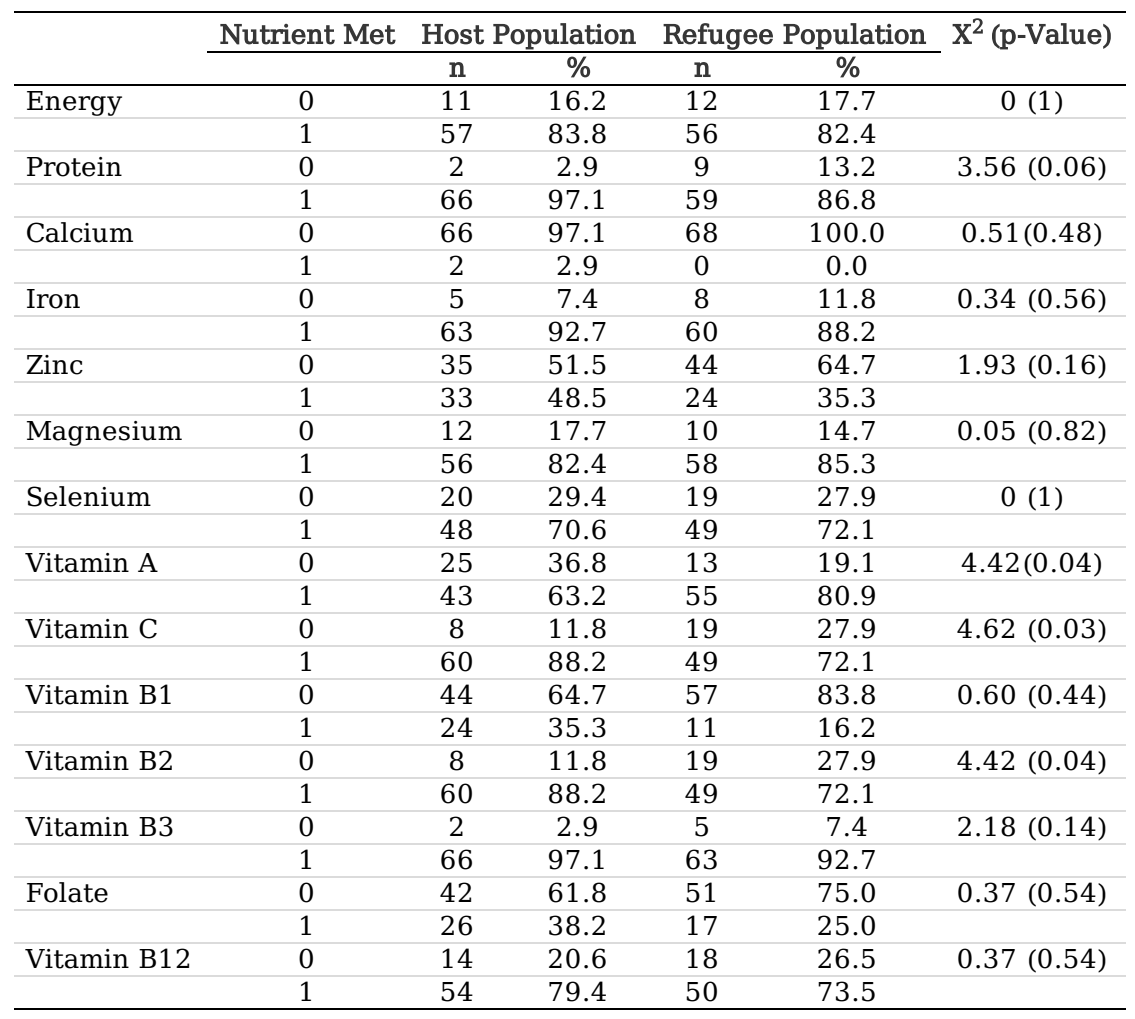

n sample size; $\mathrm{x}^{2}$ Chi square value; \% percentage; 0 nutrient not met; 1 nutrient met

\section{Discussion}

To the best of the researchers' knowledge, this is one of the most recent comprehensive studies that contextualizes the nutritional status and associated factors among host children, aged 6-59 months, vis-à-vis their spatial and temporal coexisting refugee children. While acknowledging the need to first establish the status quo of the nutritional status and associated factors among the host and refugee children population, the study also elicited dimensions of discrimination against host children. This study, determined the differences in the nutritional status and associated factors among the two-population group three years after the arrival of South Sudanese refugees in Bidi Bidi Settlement in 2016. With the current immigration crisis in Uganda and other parts of the globe, this is a critical subject from policy perspective.

The GAM prevalence in Bidibidi settlement and the neighboring host population of $3.9 \%$ is below the national average (4\%) and West Nile region $10 \%$ (19). According to WHO (2006) (20), GAM level below 5\% is acceptable thus, overall, the prevalence of acute malnutrition in Bidi Bidi Refugee Settlement was acceptable. The findings of the study agree with those of similar studies; conducted in Jordan, Lebanon and Iraq where the GAM levels were below $5 \%$ (21). A similar study by Hossain (2016) (22) in Lobule refugee settlement in the West Nile region of Uganda found GAM prevalence of $1.1 \%$. The nutritional status of children in the refugee settlement and the host community were comparable to a study done among Syrian refugees and the host (23). The prevalence of stunting among the host population, $27.0 \%$ compared to the refugees $22.4 \%$ were higher. The height difference could be that the South Sudanese refugees had better genetic traits for height compared to the host population (24). The scaled nutrition intervention in the settlement, that was not available among the host population, afforded better nutrition services for the refugee child population (25).

Investing in the first 1000 days of life is an important intervention in reduction of child stunting and a window of opportunity to improve child growth and neuro development from conception until the child's second birthday (26). Behavior change and communication to the population is an important component of nutrition education where food scarcity is a huge challenge and this can help reduce child stunting. Underweight in the study setting was $14.1 \%$ for both population groups. The similarity in the prevalence of underweight could be attributed to its pseudo chronic nature.

In a hierarchical order, five factors majorly contributed to poor nutritional status in the study setting: household size (medium or large household), illness within 14 days of the study, being a host and lack of deworming. These findings concur with those of Berhanu (2018) (27) that reported high levels of stunting in large households. Households with many members were at a higher risk of food insecurity as portion intake and size was reduced and children 6-59 months of age were particularly affected (27). On one hand, when the household size is large, infants and young children get little attention especially in their food intake and feeding habits (28). The findings of this study are consistent with those of Oromia State study in Ethiopia (29). Child sickness, 14 days, within the study affected nutritional status (wasting, stunting and underweight) of the study children. Disease weakens appetite of children and results in less food intake and illnesses that involve vomiting affects nutritional status to a larger extent. Additionally, mothers or caregivers of the children give more time to stay with the children and less time is accorded to prepare food for the children during sickness (30). Being a host was a potential risk factor to malnutrition, this study agrees with the findings by Aaby et al. (1999) in Guinea-Bissau (31). In addition to providing their farmlands to settle the refugees, the host were not provided with $50 / 50$ relief aid in the study area. Relief distribution was $70 / 30$, for the refugees and the host respectively as per Uganda's refugee policy. This 
applies for other services and excludes relief food. The findings from this study also exhibits that anemia is an additional causative factor to poor child nutritional status in the study area $\left(\mathrm{OR}^{\mathrm{a}}=2.13 ; \mathrm{p}=0.31 ; 97.5 \% \mathrm{Cl} 0.05-9.13\right)$. This result is consistent with the study done by Lufty et al. (2016) (32) among refugee children resettled in the United State from 2004 to 2010. Anemia in refugee settlement could be attributed to the point that relief food is only limited to plant based foods with no or limited inclusion of animal food sources in the diet. Low deworming means cases of helminths in the study area were high and this could have a link to anemia in children. Adequate interventions targeting micronutrient supplementation in the settlement and the host population may complement the impact of major nutrition interventions. Iron deficiency Anemia (IDA) affects the cognitive development of children and for mothers; it leads to preterm births (32).

Other factors that influence nutritional status were child-feeding practices. In terms of DDS, the refugee children had a diverse diet compared to the host. Young children less than 36 months of age had poor DDS compared to those in the age range of 36-59 months in the host and refugee population. The findings from this study was similar to a study conducted in Ghana that found a better DDS in older children compared to young ones (33). Poor household socio-economic status is a major factor for low individual dietary diversity score among the different age groups (34). On one hand, young children have limited food options compared to the older ones. Other possible reasons for low DDS in the study area could be low maternal knowledge on the importance of different food groups for their children. Poor DDS was equally linked to high stunting and underweight in the study area.

The adequacy of nutrient intake in Bidi Bidi settlement; derived from $24 \mathrm{hr}$ recall, showed that the intake of energy giving food was good for both the refugees and host populations. The host had better protein intake compared to the refugees. Whilst the refugees had access to relief food that places them at an advantage in terms of food security, these foods are not rich in protein. The host have access to income generating activities unlike the refugees that enables them to provide protein rich foods for their households. Micronutrient intake was poor in the study area; the poorest intake was for calcium. Milk and milk products are the richest source of calcium, in this present study, the consumption of these products was low and this could be attributed to the high prices of these products in the study area. Iron and Vitamin A consumption was good in the study area. Effective home gardening of leafy vegetables afforded the study children with a good intake of Vitamin A rich foods and Iron.

\subsection{Conclusion and Recommendation}

The prevalence GAM in Bidi Bidi refugee settlement and the host population is within acceptable limits and is lower than the national rate. The children of the host are of poorer nutritional status when compared to those of refugee population thus the presence of refugees in the study area garners no additional nutritional benefit to the hosting population. In a ranked order, the following are the top four associated factors that contribute to poor nutritional status of children; household size (being medium or large), having experienced an illness episode within14 days, being a host population child and parasitic infestation (inferred from lack of deworming).

The conclusions of this study lead to the following recommendations; the government of Uganda should equally target the host children, thus formulate a policy that allows them to benefit from the apportionment of food and nutrition items during emergencies. The policy should link the host children to the refugee settlement for inclusivity so that planning adequately caters for both refugee and host children.

\section{Conclusion}

To the best of the researchers' knowledge, this is one of the most recent comprehensive studies that contextualizes the nutritional status and associated factors among host children, aged 6-59 months, vis-à-vis their spatial and temporal coexisting refugee children. While acknowledging the need to first establish the status quo of the nutritional status and associated factors among the host and refugee children population, the study also elicited dimensions of discrimination against host children. This study, determined the differences in the nutritional status and associated factors among the two-population group three years after the arrival of South Sudanese refugees in Bidi Bidi Settlement in 2016. With the current immigration crisis in Uganda and other parts of the globe, this is a critical subject from policy perspective.

The GAM prevalence in Bidibidi settlement and the neighboring host population of $3.9 \%$ is below the national average (4\%) and West Nile region $10 \%$ (19). According to WHO (2006) (20), GAM level below 5\% is acceptable thus, overall, the prevalence of acute malnutrition in Bidi Bidi Refugee Settlement was acceptable. The findings of the study agree with those of similar studies; conducted in Jordan, Lebanon and Iraq where the GAM levels were below $5 \%$ (21). A similar study by Hossain (2016) (22) in Lobule refugee settlement in the West Nile region of Uganda found GAM prevalence of $1.1 \%$. The nutritional status of children in the refugee settlement and the host community were comparable to a study done among Syrian refugees and the host (23). The prevalence of stunting among the host population, $27.0 \%$ compared to the refugees $22.4 \%$ were higher. The height difference could be that the South Sudanese refugees had better genetic traits for height compared to the host population (24). The scaled nutrition intervention in the settlement, that was not available among the host population, afforded better nutrition services for the refugee child population (25).

Investing in the first 1000 days of life is an important intervention in reduction of child stunting and a window of opportunity to improve child growth and neuro development from conception until the child's second birthday (26). Behavior change and communication to the population is an important component of nutrition education where food scarcity is a huge challenge and this can help reduce child stunting. Underweight in the study setting was $14.1 \%$ for both population groups. The similarity in the prevalence of underweight could be attributed to its pseudo chronic nature.

In a hierarchical order, five factors majorly contributed to poor nutritional status in the study setting: household size (medium or large household), illness within 14 days of the study, being a host and lack of deworming. These findings concur with those of Berhanu (2018) (27) that reported high levels of stunting in large households. Households with many members were at a higher risk of food insecurity as portion intake and size was reduced and children 6-59 months of age were particularly affected (27). On one hand, when the household size is large, infants and young children get little attention especially in their food intake and feeding habits (28). The findings of this study are consistent with those of Oromia State study in Ethiopia (29). Child sickness, 14 days, within the

Page $10 / 13$ 
study affected nutritional status (wasting, stunting and underweight) of the study children. Disease weakens appetite of children and results in less food intake and illnesses that involve vomiting affects nutritional status to a larger extent. Additionally, mothers or caregivers of the children give more time to stay with the children and less time is accorded to prepare food for the children during sickness (30). Being a host was a potential risk factor to malnutrition, this study agrees with the findings by Aaby et al. (1999) in Guinea-Bissau (31). In addition to providing their farmlands to settle the refugees, the host were not provided with 50/50 relief aid in the study area. Relief distribution was 70/30, for the refugees and the host respectively as per Uganda's refugee policy. This applies for other services and excludes relief food. The findings from this study also exhibits that anemia is an additional causative factor to poor child nutritional status in the study area $\left(\mathrm{OR}^{\mathrm{a}}=2.13 ; \mathrm{p}=0.31 ; 97.5 \% \mathrm{Cl} 0.05-9.13\right)$. This result is consistent with the study done by Lufty et al. (2016) (32) among refugee children resettled in the United State from 2004 to 2010. Anemia in refugee settlement could be attributed to the point that relief food is only limited to plant based foods with no or limited inclusion of animal food sources in the diet. Low deworming means cases of helminths in the study area were high and this could have a link to anemia in children. Adequate interventions targeting micronutrient supplementation in the settlement and the host population may complement the impact of major nutrition interventions. Iron deficiency Anemia (IDA) affects the cognitive development of children and for mothers; it leads to preterm births (32).

Other factors that influence nutritional status were child-feeding practices. In terms of DDS, the refugee children had a diverse diet compared to the host. Young children less than 36 months of age had poor DDS compared to those in the age range of 36-59 months in the host and refugee population. The findings from this study was similar to a study conducted in Ghana that found a better DDS in older children compared to young ones (33). Poor household socio-economic status is a major factor for low individual dietary diversity score among the different age groups (34). On one hand, young children have limited food options compared to the older ones. Other possible reasons for low DDS in the study area could be low maternal knowledge on the importance of different food groups for their children. Poor DDS was equally linked to high stunting and underweight in the study area.

The adequacy of nutrient intake in Bidi Bidi settlement; derived from 24hr recall, showed that the intake of energy giving food was good for both the refugees and host populations. The host had better protein intake compared to the refugees. Whilst the refugees had access to relief food that places them at an advantage in terms of food security, these foods are not rich in protein. The host have access to income generating activities unlike the refugees that enables them to provide protein rich foods for their households. Micronutrient intake was poor in the study area; the poorest intake was for calcium. Milk and milk products are the richest source of calcium, in this present study, the consumption of these products was low and this could be attributed to the high prices of these products in the study area. Iron and Vitamin A consumption was good in the study area. Effective home gardening of leafy vegetables afforded the study children with a good intake of Vitamin A rich foods and Iron.

\subsection{Conclusion and Recommendation}

The prevalence GAM in Bidi Bidi refugee settlement and the host population is within acceptable limits and is lower than the national rate. The children of the host are of poorer nutritional status when compared to those of refugee population thus the presence of refugees in the study area garners no additional nutritional benefit to the hosting population. In a ranked order, the following are the top four associated factors that contribute to poor nutritional status of children; household size (being medium or large), having experienced an illness episode within14 days, being a host population child and parasitic infestation (inferred from lack of deworming).

The conclusions of this study lead to the following recommendations; the government of Uganda should equally target the host children, thus formulate a policy that allows them to benefit from the apportionment of food and nutrition items during emergencies. The policy should link the host children to the refugee settlement for inclusivity so that planning adequately caters for both refugee and host children.

\section{Declarations}

\section{Acknowledgements}

The Office of the Prime Minister (OPM) granted access to Bidi Bidi settlement for this study. UNICEF Uganda through Yumbe District Nutrition Department provided anthropometric equipment to conduct this research. Technical support of Nobert Alaru, the 13 enumerators and welfare support from Doreen Temaiya were very helpful. The authors heartily extend their sincere gratitude for all the above support.

\section{Authors contribution}

MJ, being the principal investigator (PI), took the overall responsibility of the research project hence participated in all its facets. The co-investigators, KDMW and KMW contributed to the overall design and other facets of the study while KDMW together with PI designed the questionnaires in open data kit and ona.io platform, assisted in fieldwork and data analysis. The team then produced the manuscript ready for submission.

\section{References}

1. De Lattre-Gasquet M, Moreau C. Land Use and Food Security in 2050: a Narrow Road 6. The Global Context [Internet]. [cited 2019 Nov 1]. Available from: http://www.un.org/en/sections/member-states/growth-united-nations-membership-1945-present/

2. Martineau T, Woodward A, Sheahan K, Sondorp E. Health systems research in fragile and conflict affected states: A qualitative study of associated challenges. Heal Res Policy Syst. 2017 Jun 7;15(1).

3. Kiess L, Aldern N, Pee S de, World MB-H in a D, 2017 undefined. Nutrition in humanitarian crises. Springer [Internet]. [cited 2019 Nov 1]; Available from: https://link.springer.com/chapter/10.1007/978-3-319-43739-2_29

Page $11 / 13$ 
4. Lancet PS-T, 2017 undefined. The humanitarian system is not just broke, but broken: recommendations for future humanitarian action. Elsevier [Internet]. [cited 2019 Nov 1]; Available from: https://www.sciencedirect.com/science/article/pii/S0140673617312783

5. Carter B. Country-based pooled funds for humanitarian financing [Internet]. 2018. Available from: https://www.unocha.org/our-work/humanitarianfinancing/country-based-pooled-

6. Caroline Krafft B, Sieverding M, Salemi C, Keo C. Syrian Refugees in Jordan: Demographics, Livelihoods, Education, And Health [Internet]. 2018. Available from: www.erf.org.eg

7. https://www.ennonline.net/fex/57/unhcrglobalsensdatabase

8. Kabir R, Klugman J. Unlocking Refugee Women's Potential. 2019.

9. Policy TH-E, 2004 undefined. Seeking asylum in Europe. academic.oup.com [Internet]. [cited 2019 Nov 1]; Available from: https://academic.oup.com/economicpolicy/article-abstract/19/38/6/2926009

10. Tatah L, Delbiso TD, Rodriguez-Llanes JM, Cuesta JG, Guha-Sapir D. Impact of refugees on local health systems: A difference-in-differences analysis in Cameroon. PLoS One. 2016 Dec 1;11(12).

11. Seaman J. Management of nutrition relief for famine affected and displaced populations. Trop Doct. 1991;21:38-42.

12. https://scholar.google.com/scholar?

$\mathrm{hl}=$ en\&as_sdt=0\%2C5\&q=UNICEF+Uganda.+2018.+Nutrition+situation+analysis\%3A+Trends+in+nutrition+status\%2C+behaviours\%2C+and+interventions.

13. https://reliefweb.int/.../food-security-and-nutrition-assessment-refugee-settlements-fina...

14. Bezatu Mengiste HK. Prevalence of Acute Malnutrition and its Associated Factors among Children aged 6-59 months in Mai-Aini Eritrean Refugees' Camp, Northern Ethiopia. J Nutr Food Sci [Internet]. 2014 [cited 2019 Nov 1];05(01). Available from: https://www.omicsonline.org/openaccess/prevalence-of-acute-malnutrition-and-its-associated-factors-among-2155-9600-5-336.php?aid=36181

15. Corbett M, Strategy AO-UGN, 2006 undefined. Acute malnutrition in protracted refugee situations: A global strategy.

16. https://scholar.google.com/scholar? $\mathrm{hl}=$ en\&as_sdt=0\%2C5\&q=NRC\%2F+CMP+\%282008\%29+Camp+Management+Tool+kit\%3A+Food+Distribution+and+non+food+items.+Norwegian+Refugee+Council\%2C+the+Camp+Management+Project.+Oslo\%2C+Norway.+\&btnG=

17. FAO. Guidelines for measuring household and individual dietary diversity. Fao. 2010. 1-60 p.

18. Of M, Services M. Republic of Kenya Ministry of Medical Services Kenya National Clinical Nutrition and Dietetics Reference Manual First Edition. 2010; (February).

19. UBOS. Area Specific Profiles Yumbe District. In: The National Population and Housing Census 2014. 2017.

20. WH WHO-O, Geneva ed., Switzerland undefined, 2006 undefined. WHO Multicentre Growth Reference Study Group 2006 . WHO child growth standards. Length/height-for-age, weight-for-age, weight-for-length, weight-for.

21. Hossain SMM, Leidman E, Kingori J, Al Harun A, Bilukha 00. Nutritional situation among Syrian refugees hosted in Iraq, Jordan, and Lebanon: cross sectional surveys. Confl Health. 2016 Nov 16;10(1):1-11.

22. D. Legason I, Dricile R. Prevalence of acute malnutrition among children ages 6-59 months: Results from a baseline nutrition survey in North-Western Uganda. J Nutr Hum Heal. 2018;02(01).

23. Pernitez-Agan S, Wickramage K, Yen C, Dawson-Hahn E, Mitchell T, Zenner D. Nutritional profile of Syrian refugee children before resettlement. Confl Health. 2019 Jun 4;13(1).

24. Lettre G. Recent progress in the study of the genetics of height. Hum Genet. 2011 May;129(5):465-72.

25. Dubois L, Ohm Kyvik K, Girard M, Tatone-Tokuda F, Pérusse D, Hjelmborg J, et al. Genetic and environmental contributions to weight, height, and bmi from birth to 19 years of age: An international study of over 12,000 twin pairs. PLoS One. 2012 Feb 8;7(2).

26. de Onis M, Branca F. Childhood stunting: A global perspective. Vol. 12, Maternal and Child Nutrition. Blackwell Publishing Ltd; 2016. p. $12-26$.

27. Berhanu G, Mekonnen S, Sisay M. Prevalence of stunting and associated factors among preschool children: A community based comparative cross sectional study in Ethiopia. BMC Nutr. 2018 Dec;4(1).

28. Asfaw M, Wondaferash M, Taha M, Dube L. Prevalence of undernutrition and associated factors among children aged between six to fifty nine months in Bule Hora district, South Ethiopia. BMC Public Health. 2015 Dec 12;15(1).

29. Alemu KA, Mengistu K, Alemu K, Destaw B. mHealth Interventions to Improve TB Treatment View project Integrating Real Time Health Data for Evidence Based Decision, Quality Improvement of Health Care Services, Research and Teaching in Amhara Regional State View project Thesis Open Access Prevalence of Malnutrition and Associated Factors Among Children Aged 6-59 Months at Hidabu Abote District, North Shewa, Oromia Regional State. J Nutr Disord Ther [Internet]. 2013 [cited 2019 Nov 1];1. Available from: https://www.researchgate.net/publication/307949936

30. Bo L, Samuel FO, Lawal O. 4235 Determinants of Nutritional Status of Children in Farming Households in Oyo State, Nigeria. 2010.

31. Aaby P, Gomes J, Fernandes M, Djana Q, Lisse I, Jensen H. Study in Guinea-Bissau. 1999;319(October).

32. Lutfy C, Cookson ST, Talley L, Rochat R. Malnourished children in refugee camps and lack of connection with services after US resettlement. J Immigr Minor Heal. 2014;16(5):1016-22.

33. Bandoh DA, Kenu E. Dietary diversity and nutritional adequacy of under-fives in a fishing community in the central region of Ghana. BMC Nutr. 2017 Dec;3(1).

34. Aemro M, Mesele M, Birhanu Z, Atenafu A. Dietary diversity and meal frequency practices among infant and young children aged 6-23 months in Ethiopia: A secondary analysis of Ethiopian Demographic and Health Survey 2011. J Nutr Metab. 2013;2013. 
Figures

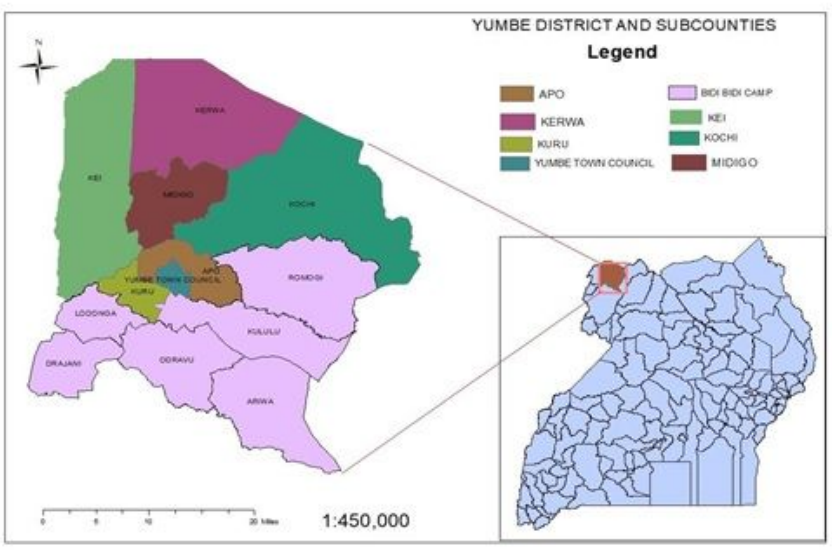

Figure 1

Map of Uganda showing the study setting 